\title{
Screening for Major Depressive Disorder in Children and Adolescents: A Systematic Review for the U.S. Preventive Services Task Force
}

\author{
Valerie Forman-Hoffman, PhD, MPH; Emily McClure, MSPH; Joni McKeeman, PhD; Charles T. Wood, MD; \\ Jennifer Cook Middleton, PhD; Asheley C. Skinner, PhD; Eliana M. Perrin, MD, MPH; and Meera Viswanathan, PhD
}

Background: Major depressive disorder (MDD) is common among children and adolescents and is associated with functional impairment and suicide.

Purpose: To update the 2009 U.S. Preventive Services Task Force (USPSTF) systematic review on screening for and treatment of MDD in children and adolescents in primary care settings.

Data Sources: Several electronic searches (May 2007 to February 2015) and searches of reference lists of published literature.

Study Selection: Trials and recent systematic reviews of treatment, test-retest studies of screening, and trials and large cohort studies for harms.

Data Extraction: Data were abstracted by 1 investigator and checked by another; 2 investigators independently assessed study quality.

Data Synthesis: Limited evidence from 5 studies showed that such tools as the Beck Depression Inventory and Patient Health Questionnaire for Adolescents had reasonable accuracy for identifying MDD among adolescents in primary care settings. Six trials evaluated treatment. Several individual fair- and good- quality studies of fluoxetine, combined fluoxetine and cognitive behavioral therapy, escitalopram, and collaborative care demonstrated benefits of treatment among adolescents, with no associated harms.

Limitation: The review included only English-language studies, narrow inclusion criteria focused only on MDD, high thresholds for quality, potential publication bias, limited data on harms, and sparse evidence on long-term outcomes of screening and treatment among children younger than 12 years.

Conclusion: No evidence was found of a direct link between screening children and adolescents for MDD in primary care or similar settings and depression or other health-related outcomes. Evidence showed that some screening tools are accurate and some treatments are beneficial among adolescents (but not younger children), with no evidence of associated harms.

Primary Funding Source: Agency for Healthcare Research and Quality.

Ann Intern Med. 2016;164:342-349. doi:10.7326/M15-2259 www.annals.org For author affiliations, see end of text.

This article was published at www.annals.org on 9 February 2016.
M ajor depressive disorder (MDD) is relatively common in childhood and adolescence and is associated with functional impairment and suicide. Nationally representative samples have indicated a past-year prevalence of approximately $8 \%$ for adolescents $(1,2)$ and roughly $3 \%$ in younger children (aged 8 to 15 years) (3). The prevalence of depression in primary care settings may be twice that of community samples of children and adolescents (4) and seems to be increasing (5). In addition, nationally representative studies have indicated that fewer than one half of children and adolescents with major depression receive treatment for mental health issues $(2,3,6)$.

Primary care providers can play a critical role in identifying depression among children and adolescents, particularly because youth with mental health issues frequently use primary care services. Because primary care providers are often the first point of professional contact for children and their families during times of distress, they can facilitate early identification of mental health issues; begin initial management; and refer children, as necessary, for further mental health

\section{See also:}

Related article . . . . . . . . . . . . . . . . . . . . . . 360

Editorial comment . . . . . . . . . . . . . . . . . . 372

342 Annals of Internal Medicine • Vol. 164 No. 5 • 1 March 2016 assessment and treatment. They also serve vital roles in collaborative care and practice networks that include mental health specialists.

Schools are also important in identifying and treating depression in children and adolescents. In 2011, $12 \%$ of adolescents aged 12 to 17 years reported receiving mental health care at school (2).

Early identification and treatment may be particularly important because of the long-term and recurrent nature of MDD (7) and its myriad negative sequelae. Associated functional impairment; decreased academic performance; and troubled relationships with parents, siblings, and peers are common and can affect developmental trajectories $(8,9)$. In addition, children and adolescents with depression are likely to have other comorbid mental health problems (7, 10); somatic symptoms, such as headache and migraine, stomach aches, and musculoskeletal pain; and chronic medical conditions, such as asthma and diabetes (11). Childhood and adolescent MDD is associated with increased risk for suicidal thoughts, attempts, and completions (12).

In 2009, the U.S. Preventive Services Task Force (USPSTF) guidelines recommended routine screening for depression in children and adolescents aged 12 to 18 years in primary care settings when resources are available for additional evaluation and care $(13,14)$. Although most experts from family medicine, pediatrics, 
nursing, psychology, and child psychiatry endorse routine surveillance for youth at high risk for depression (15), routine universal screening is still debated. Some pediatricians report discomfort with screening for and diagnosing depression, citing lack of self-efficacy, training, or experience specific to delivering mental health care (16). Some providers are also concerned about access to mental health services for patients with positive screening results.

The objective of this report is to update the recommendations released in 2009 for screening adolescents and children for MDD in primary care and similar settings (such as school-based clinics).

\section{MeTHODS}

\section{Scope of the Review}

We searched for evidence on the benefits and harms of screening; accuracy of feasible screening tests; and potential benefits and risks of treating MDD using collaborative care, psychotherapy, or selective serotonin reuptake inhibitors (SSRIs) among children and adolescents seen in primary care or similar settings, such as school-based clinics. We also wanted to determine whether the benefits and harms differed by age, sex, or race/ethnicity. Appendix Tables 1 and 2 and Appendix Figures 1 and 2 (available at www.annals .org) show key questions; search strings; analytic framework; and numbers of identified articles, screened articles, eligible articles for full-text review, and included articles organized as a PRISMA (Preferred Reporting Items for Systematic Reviews and MetaAnalyses) tree (for studies published since May 2007, the end date for the 2009 review's searches).

\section{Data Sources and Searches}

We searched PubMed (MEDLINE), the Cochrane Library, and Psychlnfo for English-language articles published from May 2007 to 4 February 2015. Unpublished literature was identified via searches of ClinicalTrials. gov, Health Services Research Projects in Progress, and the World Health Organization's International Clinical Trials Registry Platform. We also reviewed and included, as appropriate, studies from reference lists of pertinent review articles and all literature suggested by peer reviewers or public comment respondents. Appendix Table 1 and the full evidence report (available at www.uspreventiveservicestaskforce.org) include all of the search strategies used for each key question and the databases searched.

Two investigators independently reviewed titles and abstracts. We dually and independently reviewed the full text of studies that at least 1 reviewer indicated as potentially meeting our prespecified criteria for each key question, according to initial abstract review. To reduce heterogeneity and ensure focus on children and adolescents with more serious symptoms because they are more likely to have severe functional impairment and suicidality, we restricted inclusion of efficacy and harms studies to those in which at least $50 \%$ of participants had an MDD diagnosis. Screening accu- racy studies had to be done in primary care or similar settings, be of feasible length and format to administer in a setting similar to primary care, and include a comparison against a gold-standard assessment tool. We included randomized and nonrandomized trials published between May 2007 and 4 February 2015 and systematic reviews published between January 2011 and 4 February 2015 of MDD treatment efficacy and harms, test-retest studies of screening for MDD, and cohort studies with at least 1000 participants for studies of screening and treatment harms.

In addition to the new literature searches, we also applied, dually and independently, the inclusion and exclusion criteria described previously to all studies from the 2009 review (17), which included articles published from 1990 to May 2007 that focused on screening for and treatment of depression, but not specifically $M D D$, in children and adolescents. The exact differences between the inclusion and exclusion criteria applied in the current and former reviews are documented in the full evidence report at www.uspreventive servicestaskforce.org.

\section{Data Extraction and Quality Assessment}

Using predefined criteria developed by the USPSTF and others for additional criteria for diagnostic accuracy studies, 2 investigators independently assessed the quality of each study as good, fair, or poor (18). We resolved disagreements by discussion and consensus. For screening accuracy studies, flaws that resulted in poor-quality ratings included use of an inappropriate reference standard, improper administration of the screening test, biased ascertainment of the reference standard, very small sample size, or very narrowly selected spectrum of patients. For treatment efficacy and harms studies, flaws that resulted in poorquality ratings included high overall attrition (at least $20 \%$ ) or differential attrition (at least 15\%) between study groups, unreliable or invalid measurement instruments or unequal application across study groups (including not masking outcome assessment), and little or no attention given to key confounders; and, for randomized, controlled trials, the lack of an intention-totreat analysis. We excluded all studies dually determined to be of poor quality. We rated the overall body of evidence for each key question using the system developed by the USPSTF (18).

\section{Data Synthesis and Analysis}

We organized our findings according to the key questions. We used Comprehensive Meta Analysis, version 3 (Biostat), to calculate effect sizes and 95\% Cls. We planned to use meta-analysis to pool the efficacy outcomes by drug (such as escitalopram trials) and drug family (such as all SSRIs), but heterogeneity across studies limited the number of combinable interventions and outcomes, which precluded the calculation of pooled estimates.

\section{Role of the Funding Source}

The Agency for Healthcare Research and Quality funded this study under a contract to support the work 


\begin{tabular}{|c|c|c|c|c|c|}
\hline Johnson et al, 2002 (40) & Fair & $403^{*}$ & $\begin{array}{l}\text { English-speaking youth with } \geq 9 \text { y of education } \\
\text { from primary care and school nurses' offices } \\
\text { in California, Ohio, New Jersey, and New York }\end{array}$ & Range: 13-18 & PHQ-A positive \\
\hline Canals et al, 2001 (21) & Fair & 290 & $\begin{array}{l}\text { All age-eligible children per municipal census } \\
\text { in urban Spain recruited and assessed } \\
\text { through schools }\end{array}$ & Range: 17-18 & $\begin{array}{l}\text { BDI score } \geq 11 \\
\text { BDI score } \geq 16\end{array}$ \\
\hline Roberts et al, 1991 (39) & Fair & 1704 & $\begin{array}{l}\text { Random sample of } 9 \text { high schools in } 5 \text { communities } \\
\text { (stratified by school) in west-central Oregon; } \\
\text { rural population oversampled to get equal urban } \\
\text { and rural proportions }\end{array}$ & Mean: 16.6 & $\begin{array}{l}\text { BDI score } \geq 11 \\
\text { CES-D score } \geq 24\end{array}$ \\
\hline Garrison et al, 1991 (23) & Fair & 332 & $\begin{array}{l}\text { Students in or transferring to designated schools } \\
\text { for middle or high school in southeastern } \\
\text { metropolitan school district; United States }\end{array}$ & Range: 11-15 & $\begin{array}{l}\text { CES-D score } \geq 22 \\
\text { CES-D score } \geq 12\end{array}$ \\
\hline
\end{tabular}

$\mathrm{BDI}=$ Beck Depression Inventory; CES-D = Center for Epidemiological Studies Depression Scale; CIDI = Composite International Diagnostic Interview; $\mathrm{CIS}-\mathrm{R}=$ Clinical Interview Schedule-Revised; $\mathrm{NR}=$ not reported; $\mathrm{PHQ}-\mathrm{A}=$ Patient Health Questionnaire for Adolescents; SCAN $=$ Schedules for Clinical Assessment in Neuropsychiatry; USPSTF = U.S. Preventive Services Task Force.

* A total of 403 patients completed screening and diagnostic interviews, but 162 were excluded because of the time lag between screening and the interview.

† The clinical validation interview included items from the Diagnostic and Statistical Manual of Mental Disorders, Third Edition, Revised, Structured Clinical Interview; Primary Care Evaluation of Mental Disorders Clinical Evaluation Guide; and Diagnostic and Statistical Manual of Mental Disorders, Fourth Edition, Global Assessment of Functioning.

$\ddagger \mathrm{Cl}$ calculated from reported SEs.

of the USPSTF. Members of the USPSTF and the Agency medical officer assisted in the development of the review's scope, key questions, and analytic framework. The Agency for Healthcare Research and Quality reviewed and approved this manuscript before publication, but the authors are solely responsible for its content and the decision to submit it for publication.

\section{RESUlts}

Only 2 new treatment efficacy studies met our criteria $(19,20)$. The studies included in the 2009 review, when re-reviewed against our criteria, yielded 5 studies on screening accuracy (21-24) and 4 trials in 6 publications on treatment efficacy ( 3 publications on 1 trial [25-27] and 1 publication each on the other 3 trials [28-30]).

\section{Benefits, Yield, and Harms of Screening}

We found no trials that directly assessed the benefits or harms of screening children or adolescents for MDD in primary care settings. We also did not find studies that addressed whether screening increases the proportion of children or adolescents identified with MDD or results in harms.

No meta-analyses or retrospective cohort studies met our inclusion criteria. We excluded studies if less than half of the sample of children and adolescents had MDD or did not report outcomes for those with MDD separately (31-34). We also excluded studies (35-38) that evaluated paroxetine as a treatment method because its use is contraindicated among children and adolescents due to concern for increased risk for suicidality.

\section{Accuracy of Screening Instruments}

Five fair-quality studies included in the 2009 review, but no studies published since, met our inclusion and quality criteria $(21,23,24,39,40)$ (Table 1) for accuracy of screening instruments. These 5 studies examined such instruments as the Patient Health Questionnaire for Adolescents, Beck Depression Inventory (BDI), Center for Epidemiologic Studies Depression Scale, and Clinical Interview Schedule-Revised questionnaire. Four studies were done in schools, and 1 was done in a primary care setting. No study included children younger than 11 years.

In summary, the Patient Health Questionnaire for Adolescents and BDI reported the highest sensitivity (range, $73 \%$ to $90 \%$ ) and specificity (range, $81 \%$ to $94 \%)(21,39,40)$. Across all tests and studies, the positive predictive value was low and variable, ranging from $8 \%$ to $56 \%$. The negative predictive value was 91\% for the Clinical Interview Schedule-Revised questionnaire (24), greater than $99 \%$ for both studies of BDI that used a consistent cutoff score of $11(21,39)$, and 99\% for the Center for Epidemiologic Studies Depression Scale $(23,39)$. With respect to subgroup differences, we found inconsistent results for sex differences in accuracy, with 1 study finding greater sensitivity and specificity for boys (39) and the other for girls (23).

\section{Benefits and Harms of Treatment}

Six trials reported in 8 publications ( 4 trials reported in 6 publications included in the 2009 review [25-30] and 2 newer studies [19, 20]) met our inclusion criteria for benefits and harms of treatment. Interventions were tested, including SSRIs (fluoxetine, escitalopram, and citalopram), cognitive behavioral therapy 


\begin{tabular}{|c|c|c|c|c|c|}
\hline \multicolumn{6}{|c|}{ Table 1-Continued } \\
\hline Sensitivity, \% & Specificity, \% & Prevalence, \% & $\begin{array}{l}\text { Positive } \\
\text { Predictive } \\
\text { Value, \% }\end{array}$ & $\begin{array}{l}\text { Negative } \\
\text { Predictive } \\
\text { Value, \% }\end{array}$ & $\begin{array}{l}\text { Area Under the Curve } \\
(95 \% \mathrm{Cl})\end{array}$ \\
\hline 73 & 94 & Assumed current: 9.4† & 56 & 97 & NR \\
\hline $\begin{array}{l}90 \\
90\end{array}$ & $\begin{array}{l}86 \\
96\end{array}$ & $\begin{array}{l}\text { Current: } 3.4 \text { (SE, } 1.4 \text {; SCAN, seems } \\
\text { to be weighted for selection) } \\
\text { (49) }\end{array}$ & $\begin{array}{l}20 \\
47\end{array}$ & $\begin{array}{l}99.5 \\
99.6\end{array}$ & NR \\
\hline 84 & $\begin{array}{l}81 \\
75\end{array}$ & Weighted data NR & $\begin{array}{r}10 \\
8\end{array}$ & $\begin{array}{l}99.5 \\
99.0\end{array}$ & $\begin{array}{l}\text { Male: } 0.93(0.84-1.02) \ddagger ; \\
\quad \text { female: } 0.83(0.75-0.91) \ddagger \\
\text { Male: } 0.87(0.75-0.99) \ddagger ; \\
\text { female: } 0.83(0.75-0.91) \ddagger\end{array}$ \\
\hline $\begin{array}{l}18 \text { (male); } 83 \text { (female) } \\
85 \text { (male); } 84 \text { (female) }\end{array}$ & $\begin{array}{l}83 \text { (male); } 77 \text { (female) } \\
49 \text { (male); } 38 \text { (female) }\end{array}$ & Weighted data NR & $\begin{array}{l}9 \text { (male); } 25 \text { (female) } \\
13 \text { (male); } 11 \text { (female) }\end{array}$ & NR (male and female) & Male: $0.61 ;$ female: 0.77 \\
\hline 18 & 97 & $\begin{array}{l}\text { Current: } 6.2 \text { (95\% Cl, 0.3-11.8) } \\
\text { Past } 6 \text { mo: } 12.1 \text { ( } 95 \% \mathrm{Cl}, 5.0-19.3) \\
\text { (CIDI, estimate weighted for } \\
\text { selection) }\end{array}$ & 49 & 91 & NR \\
\hline
\end{tabular}

(CBT), fluoxetine combined with CBT, and collaborative care. We rated 1 trial included in the 2009 review (TADS [the Treatment for Adolescents With Depression Study]) and 3 publications that met inclusion criteria and reported on different outcomes, as good quality (25-27). The authors reported benefits and harms of 3 interventions (fluoxetine only, CBT only, and combined fluoxetine and CBT) compared with placebo among adolescents aged 12 to 17 years. Two fair-quality, placebo-controlled trials that studied escitalopram met inclusion criteria. One was a previously reported trial (in the 2009 review) done among children and adolescents aged 6 to 17 years (28), and the other was a new trial done among adolescents aged 12 to 17 years (19). The fourth trial tested citalopram versus placebo in a sample of children and adolescents aged 7 to 17 years (29) and was included in the 2009 review. The fifth trial included in the prior review focused on testing a CBT intervention among adolescents aged 14 to 18 years (30). A sixth recently published trial tested the efficacy of a collaborative care intervention done in 9 pediatric and family medicine clinics among adolescents aged 13 to 17 years (20). None of the psychotherapy or combined intervention trials included children younger than 12 years. In addition, with 1 exception, all trials lasted 8 to 12 weeks; only the collaborative care trial examined longer-term outcomes (Table 2).

One good-quality trial (TADS) found significant associations between fluoxetine and response to treatment (25) (absolute risk difference, 25.7\%) and between the combined fluoxetine and CBT intervention and response (absolute risk difference, 36.2\%). Thus, evidence from this trial suggests that fluoxetine may be associated with large effect sizes in the acute phase. One of the 2 included escitalopram trials demonstrated efficacy, although the effect sizes for response to treatment were notably smaller than those for the fluoxetine trial. In addition, this escitalopram trial was the only one that examined efficacy by age group (but not by sex, race, or ethnicity) by testing differences in efficacy and then separately reported outcomes for adolescents aged 12 to 17 years and children aged 6 to 11 years (28). Among children, the study found no significant differences between groups in depression symptoms or severity. However, among adolescents, all depression symptom and severity outcomes, except the Children's Depression Rating Scale-Revised (CDRS-R) score, differed significantly by treatment group.

Neither of the 2 psychotherapy trials (both done on adolescents) published in 4 publications demonstrated efficacy of CBT $(25-27,30)$. In contrast, the combined fluoxetine and CBT group of TADS found significant differences in response $(71.0 \%$ vs. $34.8 \% ; P=0.001$; relative risk, 2.04), including number of depressive symptoms, remission, global functioning, global burden of psychiatric problems, and quality of life at 12week follow-up, compared with the placebo group (2527). The collaborative care trial found that intervention patients had significant decreases in mean CDRS-R scores at 6 months $(-8.5)$ and 12 months $(-9.4)$. They were also more likely to achieve response at both 6 months (odds ratio, 5.2) and 12 months (odds ratio, 3.9 ) and remission at 12 months (odds ratio, 3.3) than control patients.

All but 1 efficacy trial provided information on harms. One good-quality study, TADS (25), found no significant differences for harm-related adverse events (AEs) or suicide-related AEs between the fluoxetine, CBT, or combined fluoxetine and CBT group and the placebo group. The rate of discontinuation due to $A E s$, serious AEs (SAEs), AEs suggestive of self-harm, suicidality, or laboratory values or tests did not differ significantly between the escitalopram and placebo groups in 1 trial (19), other than a greater decrease in platelet counts in the escitalopram group. The second escitalopram fair-quality trial (28) reported 2 SAEs and 1 potentially suicide-related event in the escitalopram group and 3 SAEs and 2 potentially suicide-related events in the placebo group. These differences were not statistically significant. The fair-quality citalopram trial (29) reported no significant difference between groups in overall discontinuation ( $20 \%$ in the citalopram group 
Table 2. Pooled Estimates of Efficacy Outcomes in Randomized, Controlled Trials Among Children and Adolescents With MDD

\begin{tabular}{|c|c|c|c|c|c|c|}
\hline Study, Year (Reference) & Pharmacotherapy & $\begin{array}{l}\text { Patients } \\
\text { Randomly } \\
\text { Assigned, } n\end{array}$ & Age Range, $y$ & $\begin{array}{l}\text { Length of } \\
\text { Intervention, wk }\end{array}$ & \multicolumn{2}{|c|}{ Response Rate, \% } \\
\hline $\begin{array}{l}\text { March et al, } 2004(25) \\
\text { Kennard et al, } 2006(26) \\
\text { Vitiello et al, } 2006 \text { (27) }\end{array}$ & Fluoxetine & 221 & 12 to 17 & 12 & 60.6 & 34.8 \\
\hline Wagner et al, 2004 (29) & Citalopram & 178 & 7 to 17 & 8 & 47.2 & 44.7 \\
\hline $\begin{array}{l}\text { March et al, } 2004 \text { (25) } \\
\text { Kennard et al, } 2006 \text { (26) } \\
\text { Vitiello et al, } 2006 \text { (27) }\end{array}$ & CBT & 223 & 12 to 17 & 12 & 43.2 & 34.8 \\
\hline Clarke et al, $1999(30)$ & CBT & 123 & 14 to 18 & 8 & 66.7 & 48.1 \\
\hline $\begin{array}{l}\text { March et al, } 2004 \text { (25) } \\
\text { Kennard et al, } 2006(26) \\
\text { Vitiello et al, } 2006 \text { (27) }\end{array}$ & Fluoxetine and CBT & 219 & 12 to 17 & 12 & 71.0 & 34.8 \\
\hline
\end{tabular}

$\mathrm{CBT}=$ cognitive behavioral therapy; CDI-S = Children's Depression Inventory-Short Version; CDRS-R = Children's Depression Rating Scale-Revised; CGAS = Children's Global Assessment Scale; CGI-I = Clinical Global Impressions-Improvement Scale; MDD = major depressive disorder; NR = not reported.

* CGI-I score $=1$ or 2 .

† As measured by a Patient Health Questionnaire-9 score $<5$ (range, $0-27$, with higher scores indicating greater levels of depressive symptoms).

¥ As measured by the Columbia Impairment Scale (range, 0-52, with higher scores indicating greater levels of functional impairment).

vs. $21 \%$ in the placebo group) or discontinuation due to AEs ( $5.9 \%$ vs. $5.6 \%$ ) and no SAEs, including suicidality. The good-quality collaborative care trial (20) found no significant differences in the mean number of psychiatric hospitalizations or emergency department visits that were associated with primary psychiatric diagnoses for the collaborative care group compared with the control group ( $6 \%$ vs. $4 \%$ and $2 \%$ vs. $10 \%$, respectively). Although it is reassuring that none of these studies saw significant harms, the possibility of harms cannot be definitively excluded because the data were underpowered to show equivalence.

\section{Discussion}

Appendix Table 3 (available at www.annals.org) summarizes the evidence. We found no trials meeting the inclusion and quality criteria for this review that examined the overall question of whether routine screening for pediatric MDD in primary care reduced depression or improves other health-related outcomes. We found no new eligible screening studies. The subset of studies from the 2009 review that continued to meet inclusion criteria offered limited evidence. Our conclusions are consistent with that of the previous review. In short, the Patient Health Questionnaire for Adolescents and $\mathrm{BDI}$ continue to outperform other screening tools. No included studies tested more recent screening tools that are known to have good psychometric properties. In addition, some of the older studies included in this report used adult versions of screening tools that have since developed child- or adolescent-specific versions $(41,42)$. We noted that the positive predictive value of instruments examined in these studies was relatively low (range, $10 \%$ to $56 \%$ ); thus, $44 \%$ to $90 \%$ of persons with positive screening results for MDD will not, in fact, have a clinical diagnosis of MDD after further testing. Moreover, the substantial heterogeneity in interventions, populations, and settings and the lack of replication studies makes generalization of findings from these studies challenging. The gap in evidence of accurate MDD screening tools for children persists after doing this updated review. No included studies examined harms of screening or whether screening increases the proportion of children or adolescents identified with MDD.

We identified randomized, controlled trials that sought to examine the efficacy of collaborative care and SSRI interventions for children and adolescents with MDD, although not all showed significant benefit (specifically, the citalopram trial and 1 escitalopram trial showed no significant benefit). We found very limited evidence on psychotherapy. A recent network metaanalysis on different types of depression in children and adolescents (major depression, minor depression, intermittent depression, or dysthymia) found that only interpersonal therapy was more effective than control conditions at both short- and long-term follow-up; both interpersonal therapy and CBT were more effective than control conditions in the short term. The applicability of these findings to children and adolescents with screen-detected MDD is unclear (43). Overall, harms of treatment seemed to be minimal.

Limitations arise from our stringent criteria and from potential publication bias. In particular, we limited our review to English-language studies that focused solely on screening and treatment of MDD in primary care. We did not address screening or treatment of minor depression, dysthymia, or depression in subgroups 
Table 2-Continued

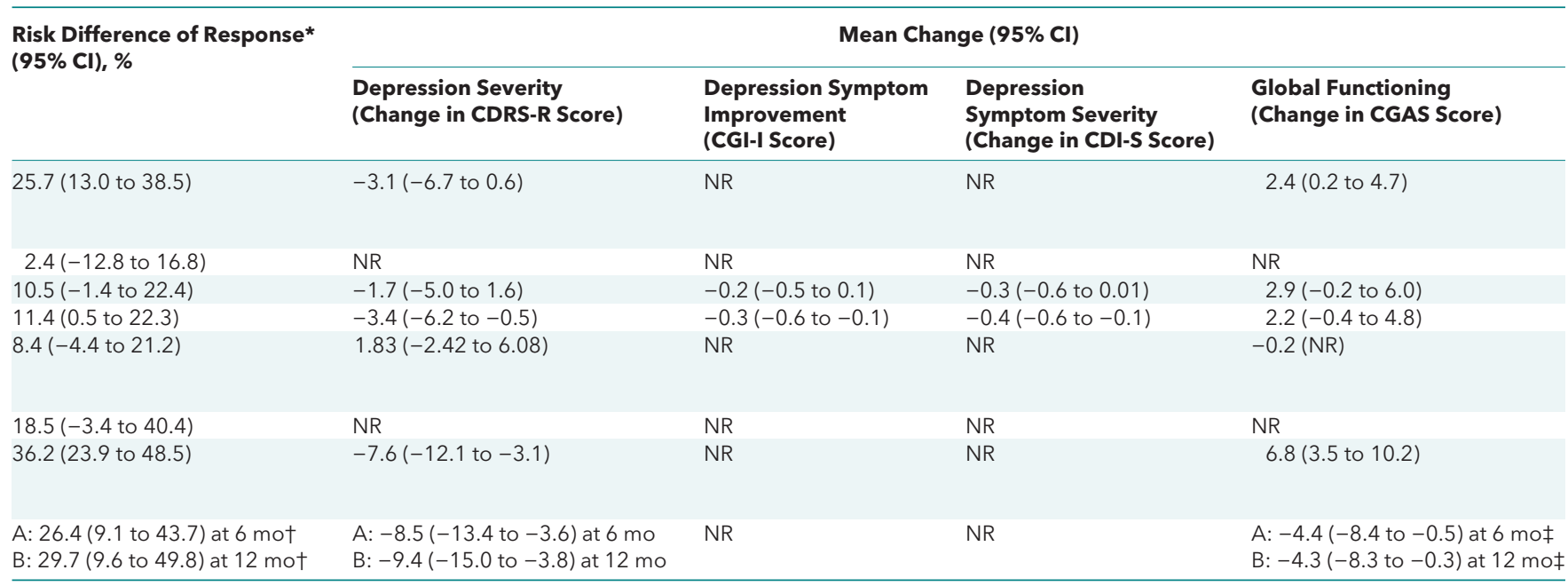

believed to be at high risk (for example, those with parental depression or comorbid mental or physical health conditions). Controversy continues about whether depressive symptoms exist on a continuous spectrum or whether MDD is a diagnostic entity of distinct clinical significance, particularly among children and adolescents (44). Although several studies have shown that subthreshold depression is a risk factor for MDD (45), its role in temporal progression to MDD is not well-understood. Studies done in adults that have quantified the risk for MDD after having subthreshold depressive symptoms have shown that approximately $8 \%$ are diagnosed with MDD in the following 3 years (46).

Primary care providers need to be aware of potential risk factors for MDD and attempt early intervention, particularly among patients who have already had an episode of major depression. The burden of universal screening requires clear evidence of net benefit for making screening recommendations. Given the paucity of evidence on the etiologic links among subthreshold depression, dysthymia, and depression, we chose to focus on screening for existing MDD rather than prevention. As noted previously, we excluded studies of paroxetine, which may have resulted in finding little overall harm from SSRIs.

Our inclusion and exclusion criteria and thresholds for quality resulted in 5 screening studies comprising nearly 2900 children and adolescents (none of whom were younger than 11 years) and 6 treatment trials with findings published in 8 papers that studied fewer than 1500 children and adolescents with MDD done over the past 3 decades. As a result, we cannot rule out the absence of benefits or harms, particularly for rare outcomes. Guidance suggests that interventions with a relative risk reduction of $20 \%$ to $25 \%$ and a control event rate of $20 \%$ require a sample size between 2000 and 4000 (47). Such outcomes as suicidality occur at much lower rates in the control group and may require even larger samples to rule out the absence of benefits and harms.

The difficulty in recruiting and enrolling children and adolescents into research studies may drive the methodological limitations of the evidence, such as small sample size, high attrition, and biased ascertainment of the reference standard in screening studies. Concerns about risks in this vulnerable population may limit funding of and enrollment within studies. High attrition is common in studies with long-term follow-up involving children and adolescents, particularly in areas of mental health. In the context of the dynamic nature of the health status of children and adolescents, a time lapse between screening and diagnostic interviews may result in biased ascertainment of the reference standard and could explain only moderate sensitivity and specificity of screening instruments.

Finally, these findings may have limited applicability to the typical primary care setting. Included studies generally drew patients from research or academic settings ranging from 1 to 40 sites. Only 1 screening accuracy study was done in a primary care setting (40); only 2 treatment trials were done predominantly in clinical settings throughout the community $(20,25)$. Thus, few primary care settings were used as the referral point or the actual intervention setting in our included studies. In addition, no school clinics served as treatment sites. Included studies had stringent inclusion and exclusion criteria, such as the exclusion of patients with several comorbidities. The patients eligible for these trials may not be representative of all patients with MDD seen in primary care.

Critical needs for future research include the following:

Populations: Benefits and harms for subgroups defined by age (especially younger than 12 years), sex, race, ethnicity, or socioeconomic status. 
Interventions: Benefits and harms from psychotherapy, non-SSRIs, complementary and alternative medicine, or combination treatments for children with MDD.

Outcomes: Accuracy of screening, whether screening increases the proportion of children and adolescents identified with depression, patients' uptake of treatment after screening and referral, harms of screening, benefits and harms of treatment, and harms of not treating MDD.

Timing: Long-term outcomes, benefits, and harms from different frequencies of screening.

Setting: Benefits and harms of screening in different locations, including studies sampling from primary care and school clinic settings.

In conclusion, these studies provide no evidence of a direct link between screening children and adolescents for MDD in primary care or similar settings and depression or other health-related outcomes. However, they do contribute evidence that some screening tools are accurate and some treatments are beneficial among adolescents (but not younger children). Although no study found significant harms associated with treatment, lack of precision hampers our ability to rule out effects. Evidence gaps sharply limit conclusions for screening children younger than 12 years; screening and treatment differences by sex, race, or ethnicity subgroups; and efficacy of MDD treatment other than SSRIs.

From RTI International, Research Triangle Park, and University of North Carolina, Chapel Hill, North Carolina.

Disclaimer: The findings and conclusions in this document are those of the authors, who are responsible for its contents, and do not necessarily represent the views of the Agency for Healthcare Research and Quality. Therefore, no statement in this report should be construed as an official position of the Agency for Healthcare Research and Quality or the U.S. Department of Health and Human Services.

Grant Support: By the Agency for Healthcare Research and Quality (contract HHSA290201200015iT02).

Disclosures: Dr. Forman-Hoffman reports other from the Agency for Healthcare Research and Quality and Substance Abuse and Mental Health Services Administration outside the submitted work. Dr. Skinner reports grants from the Agency for Healthcare Research and Quality during the conduct of the study. Dr. Perrin reports grants from the Agency for Healthcare Research and Quality during the conduct of the study. Dr. Viswanathan reports other funding from the U.S. Department of Health and Human Services and grants from the Agency for Healthcare Research and Quality during the conduct of the study. Authors not named here have disclosed no conflicts of interest. Forms can be viewed at www.acponline .org/authors/icmje/ConflictOfInterestForms.do?msNum=M15 -2259 .

Requests for Single Reprints: Valerie Forman-Hoffman, PhD, MPH, RTI International, 3040 Cornwallis Road, Research Triangle Park, NC 27709; e-mail, vhoffman@rti.org.
Current author addresses and author contributions are available at www.annals.org.

\section{References}

1. Merikangas KR, He JP, Burstein M, Swanson SA, Avenevoli S, Cui $L$, et al. Lifetime prevalence of mental disorders in U.S. adolescents: results from the National Comorbidity Survey Replication-Adolescent Supplement (NCS-A). J Am Acad Child Adolesc Psychiatry. 2010;49:980-9. [PMID: 20855043] doi:10.1016/j.jaac.2010.05.017

2. Substance Abuse and Mental Health Services Administration. Results from the 2011 National Survey on Drug Use and Health: Mental Health Findings. NSDUH Series H-45, HHS Publication No. (SMA) 12-4725. Rockville, MD: Substance Abuse and Mental Health Services Administration; 2012. Accessed at www.samhsa.gov/data/sites /default/files/2011MHFDT/2k11MHFR/Web/NSDUHmhfr2011.htm on 16 November 2015.

3. Merikangas KR, He JP, Brody D, Fisher PW, Bourdon K, Koretz DS. Prevalence and treatment of mental disorders among U.S. children in the 2001-2004 NHANES. Pediatrics. 2010;125:75-81. [PMID: 20008426] doi:10.1542/peds.2008-2598

4. Gledhill J, Garralda ME. The short-term outcome of depressive disorder in adolescents attending primary care: a cohort study. Soc Psychiatry Psychiatr Epidemiol. 2011;46:993-1002. [PMID: 20820756] doi:10.1007/s00127-010-0271-6

5. Kramer T, lliffe S, Gledhill J, Garralda ME. Recognising and responding to adolescent depression in general practice: developing and implementing the Therapeutic Identification of Depression in Young people (TIDY) programme. Clin Child Psychol Psychiatry. 2012;17:482-94. [PMID: 22523137] doi:10.1177/1359104512442639

6. Merikangas KR, He JP, Burstein M, Swendsen J, Avenevoli S, Case $B$, et al. Service utilization for lifetime mental disorders in U.S. adolescents: results of the National Comorbidity Survey-Adolescent Supplement (NCS-A). J Am Acad Child Adolesc Psychiatry. 2011;50:3245. [PMID: 21156268] doi:10.1016/j.jaac.2010.10.006

7. Rohde P, Lewinsohn PM, Klein DN, Seeley JR, Gau JM. Key characteristics of major depressive disorder occurring in childhood, adolescence, emerging adulthood, adulthood. Clin Psychol Sci. 2013;1. [PMID: 24273703] doi:10.1177/2167702612457599

8. Bang KS, Chae SM, Hyun MS, Nam HK, Kim JS, Park KH. The mediating effects of perceived parental teasing on relations of body mass index to depression and self-perception of physical appearance and global self-worth in children. J Adv Nurs. 2012;68:2646-53. [PMID: 22384945] doi:10.1111/j.1365-2648.2012.05963.x

9. Pomerantz EM, Altermatt ER, Saxon JL. Making the grade but feeling distressed: gender differences in academic performance and internal distress. J Educ Psychol. 2002;94:396-404.

10. Kessler RC, Avenevoli S, McLaughlin KA, Green JG, Lakoma MD, Petukhova M, et al. Lifetime co-morbidity of DSM-IV disorders in the US National Comorbidity Survey Replication Adolescent Supplement (NCS-A). Psychol Med. 2012;42:1997-2010. [PMID: 22273480] doi:10.1017/S0033291712000025

11. Egger HL, Costello EJ, Erkanli A, Angold A. Somatic complaints and psychopathology in children and adolescents: stomach aches, musculoskeletal pains, and headaches. J Am Acad Child Adolesc Psychiatry. 1999;38:852-60. [PMID: 10405503]

12. Substance Abuse and Mental Health Services Administration. Suicidal Thoughts among Youths Aged 12 to 17 with Major Depressive Episode. 2005. Accessed at http://media.samhsa.gov/data/2k5 /suicide/suicide.htm on 1 December 2015.

13. Zuckerbrot RA, Jensen PS. Improving recognition of adolescent depression in primary care. Arch Pediatr Adolesc Med. 2006;160: 694-704. [PMID: 16818834]

14. Williams SB, O'Connor EA, Eder M, Whitlock EP. Screening for child and adolescent depression in primary care settings: a systematic evidence review for the U.S. Preventive Services Task Force. Pediatrics. 2009;123:e716-35. [PMID: 19336361] doi:10.1542/peds $.2008-2415$ 
15. Cheung $A H$, Zuckerbrot RA, Jensen PS, Stein RE, Laraque D; GLAD PC Steering Committee. Expert survey for the management of adolescent depression in primary care. Pediatrics. 2008;121:e101-7. [PMID: 18166529] doi:10.1542/peds.2006-3560

16. Williams J, Klinepeter K, Palmes G, Pulley A, Foy JM. Diagnosis and treatment of behavioral health disorders in pediatric practice. Pediatrics. 2004;114:601-6. [PMID: 15342827]

17. Williams SB, O'Connor E, Eder M, Whitlock E. Screening for Child and Adolescent Depression in Primary Care Settings: A Systematic Evidence Review for the U.S. Preventive Services Task Force. Rockville MD: Agency for Healthcare Research and Quality; 2009.

18. Harris RP, Helfand M, Woolf SH, Lohr KN, Mulrow CD, Teutsch SM, et al; Methods Work Group, Third US Preventive Services Task Force. Current methods of the U.S. Preventive Services Task Force: a review of the process. Am J Prev Med. 2001;20:21-35. [PMID: 11306229]

19. Emslie GJ, Ventura D, Korotzer A, Tourkodimitris S. Escitalopram in the treatment of adolescent depression: a randomized placebocontrolled multisite trial. J Am Acad Child Adolesc Psychiatry. 2009; 48:721-9. [PMID: 19465881] doi:10.1097/CHI.0b013e3181a2b304

20. Richardson LP, Ludman E, McCauley E, Lindenbaum J, Larison C, Zhou $\mathrm{C}$, et al. Collaborative care for adolescents with depression in primary care: a randomized clinical trial. JAMA. 2014;312:809-16. [PMID: 25157724] doi:10.1001/jama.2014.9259

21. Canals J, Blade J, Carbajo G, Domenech-Llaberia E. The Beck Depression Inventory: Psychometric characteristics and usefulness in nonclinical adolescents. Eur J Psychol Assess. 2001;17:63-8.

22. Roberts J, Johnstone S. Screening and treating depression: patient preferences and implications for social workers. Nephrol News Issues. 2006;20:43, 47-9. [PMID: 17168058]

23. Garrison $C Z$, Addy $C L$, Jackson $K L$, McKeown RE, Waller JL. The CES-D as a screen for depression and other psychiatric disorders in adolescents. J Am Acad Child Adolesc Psychiatry. 1991;30:636-41. [PMID: 1890099]

24. Patton GC, Coffey C, Posterino M, Carlin JB, Wolfe R, Bowes G. A computerised screening instrument for adolescent depression: population-based validation and application to a two-phase casecontrol study. Soc Psychiatry Psychiatr Epidemiol. 1999;34:166-72. [PMID: 10327843]

25. March J, Silva S, Petrycki S, Curry J, Wells K, Fairbank J, et al; Treatment for Adolescents With Depression Study (TADS) Team. Fluoxetine, cognitive-behavioral therapy, and their combination for adolescents with depression: Treatment for Adolescents With Depression Study (TADS) randomized controlled trial. JAMA. 2004;292: 807-20. [PMID: 15315995]

26. Kennard B, Silva S, Vitiello B, Curry J, Kratochvil C, Simons A, et al; TADS Team. Remission and residual symptoms after short-term treatment in the Treatment of Adolescents with Depression Study (TADS). J Am Acad Child Adolesc Psychiatry. 2006;45:1404-11. [PMID: 17135985]

27. Vitiello B, Rohde P, Silva S, Wells K, Casat C, Waslick B, et al; TADS Team. Functioning and quality of life in the Treatment for Adolescents with Depression Study (TADS). J Am Acad Child Adolesc Psychiatry. 2006;45:1419-26. [PMID: 17135987]

28. Wagner KD, Jonas J, Findling RL, Ventura D, Saikali K. A doubleblind, randomized, placebo-controlled trial of escitalopram in the treatment of pediatric depression. J Am Acad Child Adolesc Psychiatry. 2006;45:280-8. [PMID: 16540812]

29. Wagner KD, Robb AS, Findling RL, Jin J, Gutierrez MM, Heydorn WE. A randomized, placebo-controlled trial of citalopram for the treatment of major depression in children and adolescents. Am J Psychiatry. 2004;161:1079-83. [PMID: 15169696]

30. Clarke GN, Rohde P, Lewinsohn PM, Hops H, Seeley JR. Cognitive-behavioral treatment of adolescent depression: efficacy of acute group treatment and booster sessions. J Am Acad Child Adolesc Psychiatry. 1999;38:272-9. [PMID: 10087688]
31. Hammad TA, Laughren T, Racoosin J. Suicidality in pediatric patients treated with antidepressant drugs. Arch Gen Psychiatry. 2006; 63:332-9. [PMID: 16520440]

32. Søndergård L, Kvist K, Andersen PK, Kessing LV. Do antidepressants precipitate youth suicide? A nationwide pharmacoepidemiological study. Eur Child Adolesc Psychiatry. 2006;15:232-40. [PMID: 16502208]

33. Olfson M, Marcus SC, Shaffer D. Antidepressant drug therapy and suicide in severely depressed children and adults: A casecontrol study. Arch Gen Psychiatry. 2006;63:865-72. [PMID: 16894062]

34. Martin A, Young C, Leckman JF, Mukonoweshuro C, Rosenheck $\mathrm{R}$, Leslie D. Age effects on antidepressant-induced manic conversion. Arch Pediatr Adolesc Med. 2004;158:773-80. [PMID: 15289250]

35. Bridge JA, lyengar S, Salary CB, Barbe RP, Birmaher B, Pincus $H A$, et al. Clinical response and risk for reported suicidal ideation and suicide attempts in pediatric antidepressant treatment: a metaanalysis of randomized controlled trials. JAMA. 2007;297:1683-96. [PMID: 17440145]

36. Kaizar EE, Greenhouse JB, Seltman H, Kelleher K. Do antidepressants cause suicidality in children? A Bayesian meta-analysis. Clin Trials. 2006;3:73-90. [PMID: 16773951]

37. Wallace AE, Neily J, Weeks WB, Friedman MJ. A cumulative meta-analysis of selective serotonin reuptake inhibitors in pediatric depression: did unpublished studies influence the efficacy/safety debate? J Child Adolesc Psychopharmacol. 2006;16:37-58. [PMID: 16553528]

38. Valuck RJ, Libby AM, Sills MR, Giese AA, Allen RR. Antidepressant treatment and risk of suicide attempt by adolescents with major depressive disorder: a propensity-adjusted retrospective cohort study. CNS Drugs. 2004;18:1119-32. [PMID: 15581382]

39. Roberts RE, Lewinsohn PM, Seeley JR. Screening for adolescent depression: a comparison of depression scales. J Am Acad Child Adolesc Psychiatry. 1991;30:58-66. [PMID: 2005065]

40. Johnson JG, Harris ES, Spitzer RL, Williams JB. The patient health questionnaire for adolescents: validation of an instrument for the assessment of mental disorders among adolescent primary care patients. J Adolesc Health. 2002;30:196-204. [PMID: 11869927]

41. Pietsch K, Allgaier AK, Frühe B, Rohde $S$, Hosie $S$, Heinrich $M$, et al. Screening for depression in adolescent paediatric patients: validity of the new Depression Screener for Teenagers (DesTeen) J Affect Disord. 2011;133:69-75. [PMID: 21497911] doi:10.1016/j.jad .2011.03.026

42. Pagano ME, Cassidy LJ, Little M, Murphy JM, Jellinek MS. Identifying psychosocial dysfunction in school-age children: the Pediatric Symptom Checklist as a self-report measure. Psychol Sch. 2000;37: 91-106. [PMID: 22328794]

43. Zhou X, Hetrick SE, Cuijpers P, Qin B, Barth J, Whittington CJ, et al. Comparative efficacy and acceptability of psychotherapies for depression in children and adolescents: A systematic review and network meta-analysis. World Psychiatry. 2015;14:207-22. [PMID: 26043339] doi:10.1002/wps.20217

44. Angst J, Merikangas K. The depressive spectrum: diagnostic classification and course. J Affect Disord. 1997;45:31-9. [PMID: 9268773]

45. Cuijpers P, Smit F. Subthreshold depression as a risk indicator for major depressive disorder: a systematic review of prospective studies. Acta Psychiatr Scand. 2004; 109:325-31. [PMID: 15049768]

46. Cuijpers $P$, de Graaf R, van Dorsselaer S. Minor depression: risk profiles, functional disability, health care use and risk of developing major depression. J Affect Disord. 2004;79:71-9. [PMID: 15023482] 47. Guyatt GH, Oxman AD, Kunz R, Brozek J, Alonso-Coello P, Rind $D$, et al. GRADE guidelines 6. Rating the quality of evidence-imprecision. J Clin Epidemiol. 2011;64:1283-93. [PMID: 21839614] doi:10 .1016/j.jclinepi.2011.01.012 


\section{Annals of Internal Medicine}

Current Author Addresses: Drs. Forman-Hoffman, McKeeman, Wood, Middleton, Skinner, Perrin, and Viswanathan and Ms. McClure: RTI International, 3040 Cornwallis Road, Research Triangle Park, NC 27709.

Author Contributions: Conception and design: V. FormanHoffman, E. McClure, C.T. Wood, A.C. Skinner, E.M. Perrin, M. Viswanathan.

Analysis and interpretation of the data: V. Forman-Hoffman, E. McClure, J. McKeeman, C.T. Wood, A.C. Skinner, E.M. Perrin, M. Viswanathan.

Drafting of the article: E. McClure, J. McKeeman, C.T. Wood, A.C. Skinner, E.M. Perrin, M. Viswanathan.

Critical revision of the article for important intellectual content: V. Forman-Hoffman, E. McClure, J. McKeeman, C.T. Wood, A.C. Skinner, E.M. Perrin, M. Viswanathan.
Final approval of the article: V. Forman-Hoffman, E. McClure, J. McKeeman, C.T. Wood, J.C. Middleton, A.C. Skinner, E.M. Perrin, M. Viswanathan.

Provision of study materials or patients: M. Viswanathan. Statistical expertise: V. Forman-Hoffman, M. Viswanathan. Obtaining of funding: V. Forman-Hoffman, E.M. Perrin, M. Viswanathan.

Administrative, technical, or logistic support: V. FormanHoffman, E. McClure, J.C. Middleton, E.M. Perrin, M. Viswanathan.

Collection and assembly of data: V. Forman-Hoffman, E. McClure, J. McKeeman, C.T. Wood, J.C. Middleton, A.C. Skinner, M. Viswanathan.

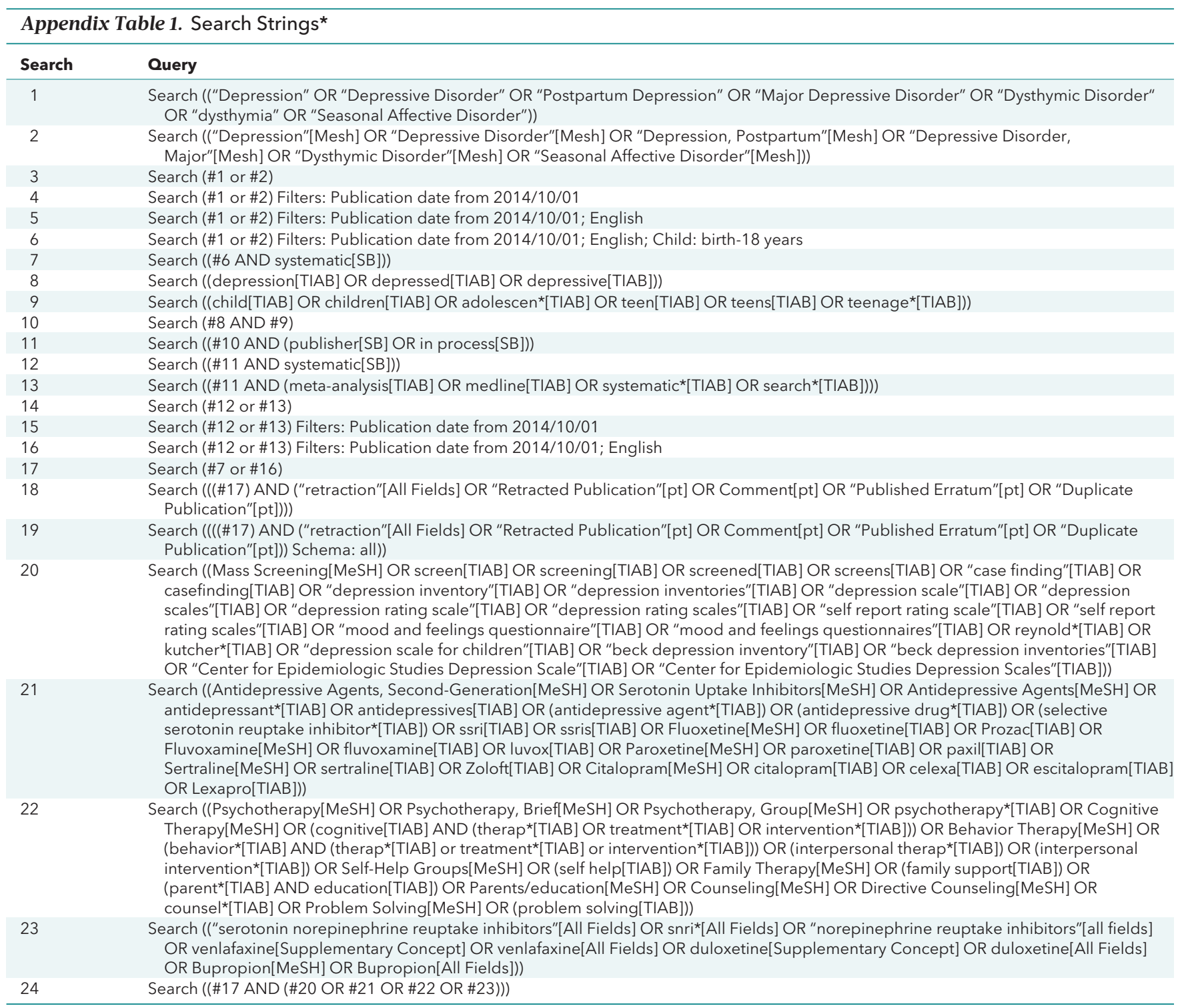

$\mathrm{MeSH}=$ Medical Subject Heading.

* Example shown is for the most recently conducted PubMed search (see report for full list of data sources). Prior queries used terms shown but limited publication dates to 2007 or later (2011 or later for systematic reviews and meta-analyses). 
Appendix Figure 1. Analytic framework for screening for childhood depression.

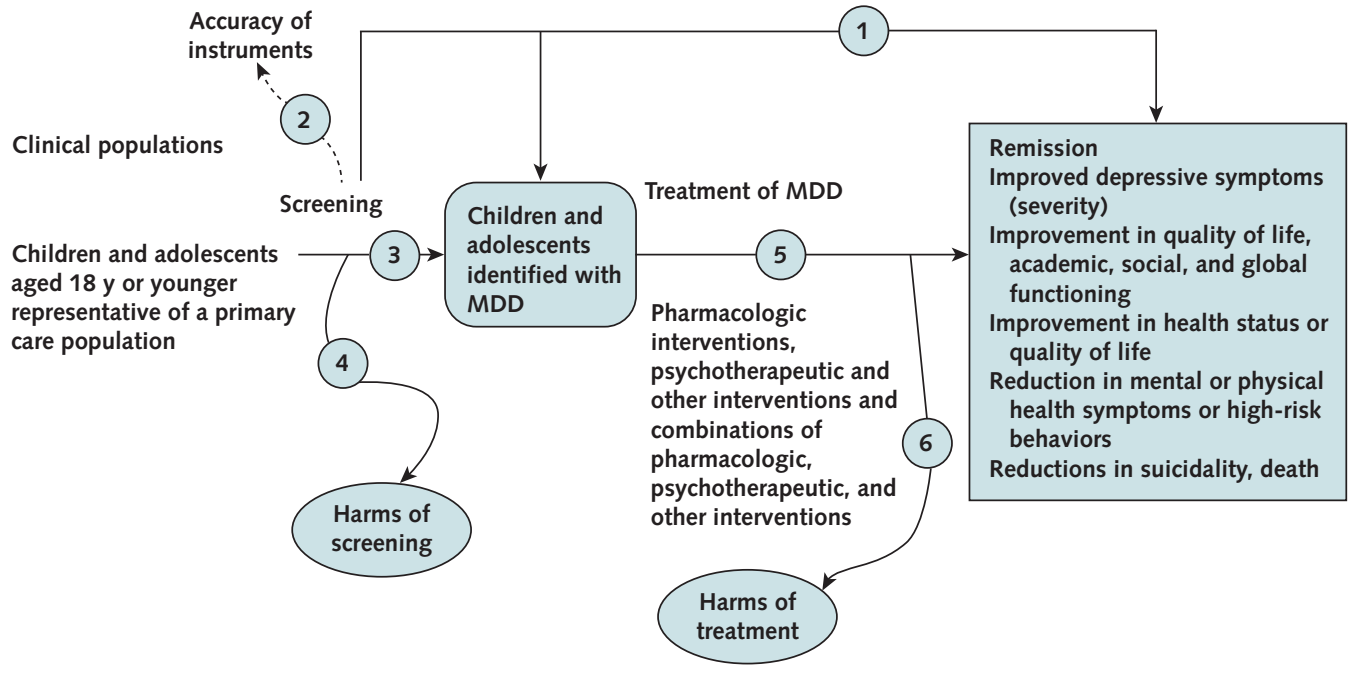

MMD = major depressive disorder

\section{Appendix Table 2. Key Questions}

1. Does screening for MDD among children and adolescents in the primary care (or comparable) setting lead to improved health and other related outcomes overall and among subgroups defined by age, sex, race, or ethnicity?

2. Are depression-screening instruments for children and adolescents accurate in identifying MDD in primary care settings overall and among subgroups defined by age, sex, race, or ethnicity?

3. Does screening increase the proportion of children and adolescents identified with MDD overall and among subgroups defined by age, sex, race, or ethnicity?

4. What are the harms of screening children and adolescents for MDD overall and among subgroups defined by age, sex, race, or ethnicity?

5. Does treatment of MDD among children and adolescents identified in primary care improve health and other related outcomes overall and among subgroups defined by age, sex, race, or ethnicity?

6. What are the harms of MDD treatment for children and adolescents overall and among subgroups defined by age, sex, race, or ethnicity?

MDD = major depressive disorder . 
Appendix Figure 2. Summary of evidence search and selection.

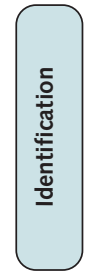

Records identified through database

searching ( $n=12816)$

PubMed: 9762

Cochrane: 1733

PsychInfo: 1321

Additional records identified through other

sources $(n=975)$

ClinicalTrials.gov: 622

HSRProj: 157

WHO ICTRP: 195

Hand search: 1

Suggestions from public comments: 0

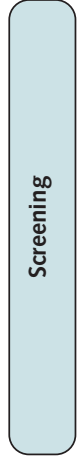

Duplicates removed $(n=3786)$
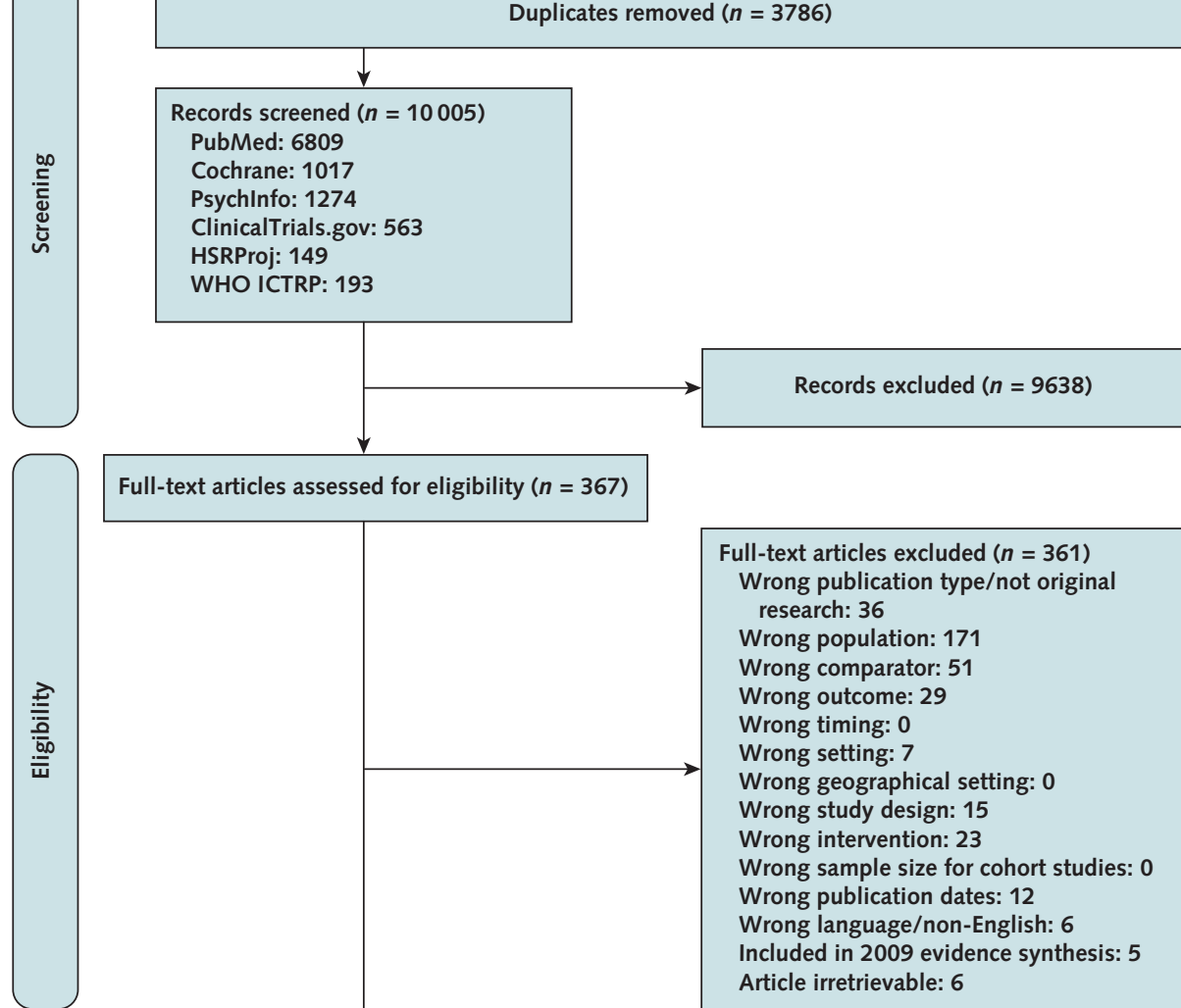

Full-text articles assessed for eligibility $(n=367)$

\begin{tabular}{l|l}
$n$ & Full-text articles excluded $(n=361)$
\end{tabular}

Wrong publication type/not original

research: 36

Wrong population: 171

Wrong comparator: 51

Wrong outcome: 29

Wrong timing: 0

Wrong setting: 7

Wrong geographical setting: 0

Wrong study design: 15

Wrong intervention: 23

Wrong sample size for cohort studies: 0

Wrong publication dates: 12

Wrong language/non-English: 6

Included in 2009 evidence synthesis: 5

Article irretrievable: 6

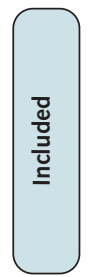

Studies from 6 articles met inclusion criteria

$(n=5)$

Poor-quality studies excluded from analysis: 3 (in 4 articles)

Fair- or good-quality studies included in quantitative synthesis: 2

Studies were published since May 2007. HSRProj = Health Services Research Projects in Progress; WHO ICTRP = World Health Organization International Clinical Trials Registry Platform. 


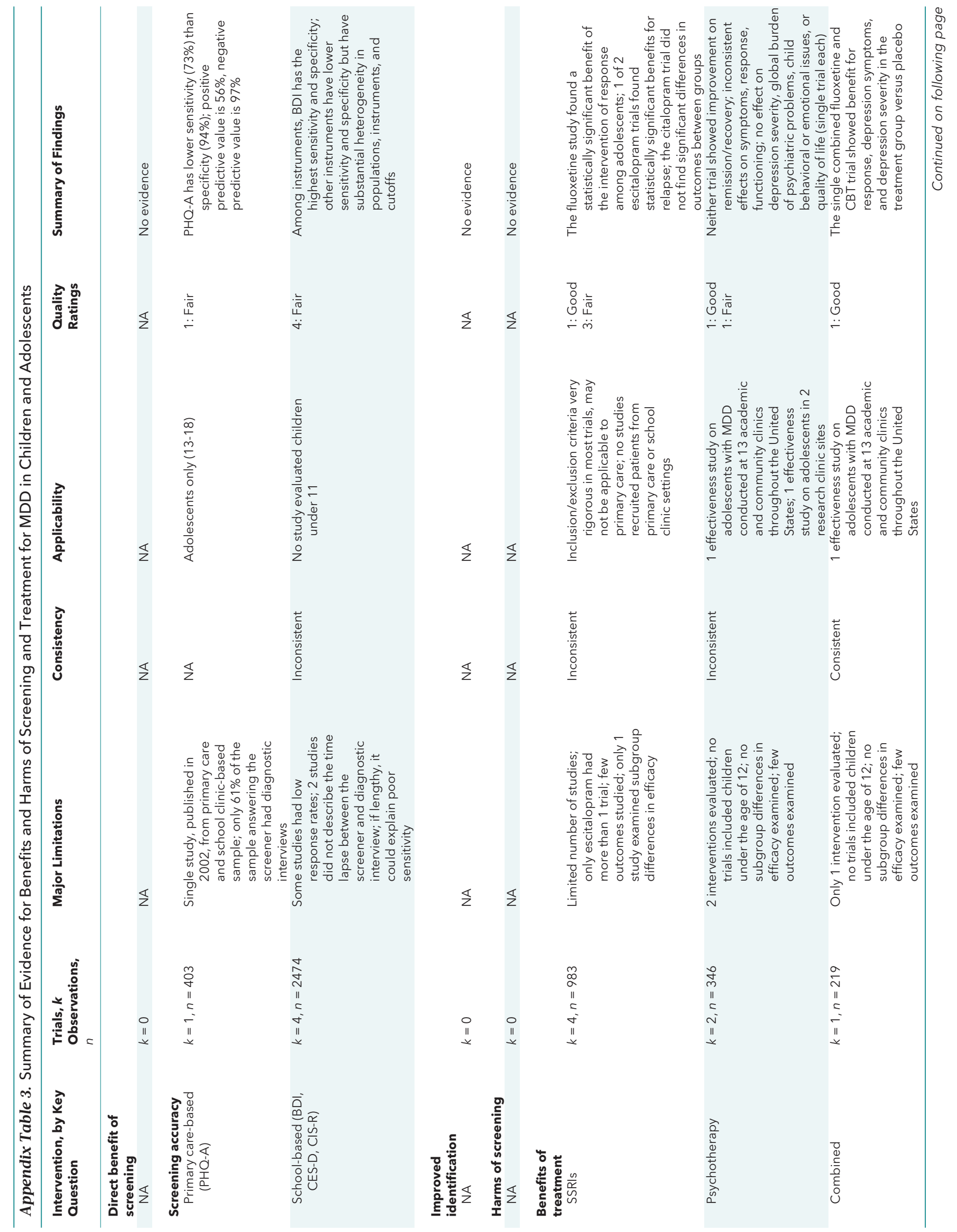

Annals of Internal Medicine • Vol. 164 No. 5 • 1 March 2016 


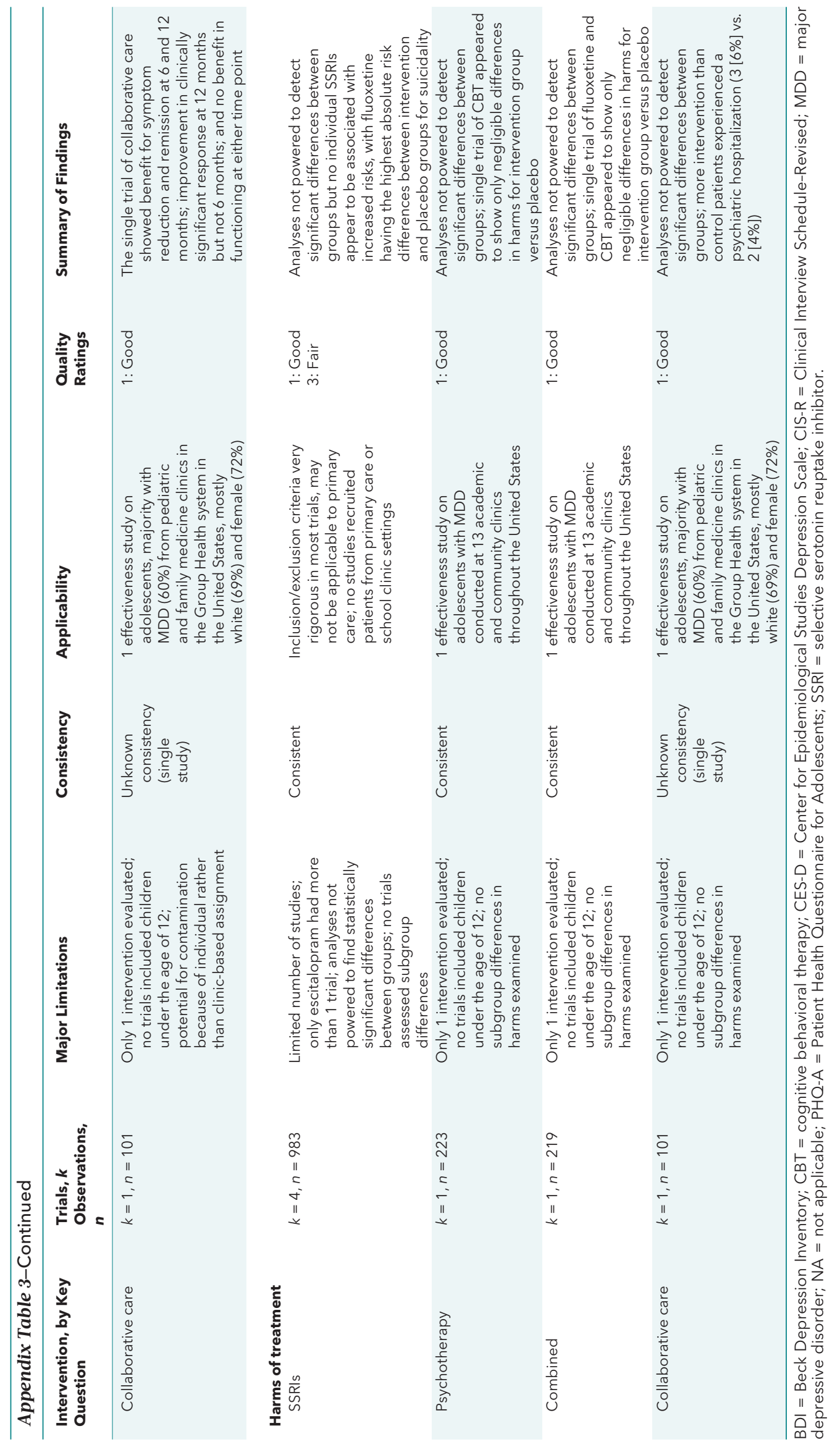

